$\mathbb{T}$ periodica polytechnica

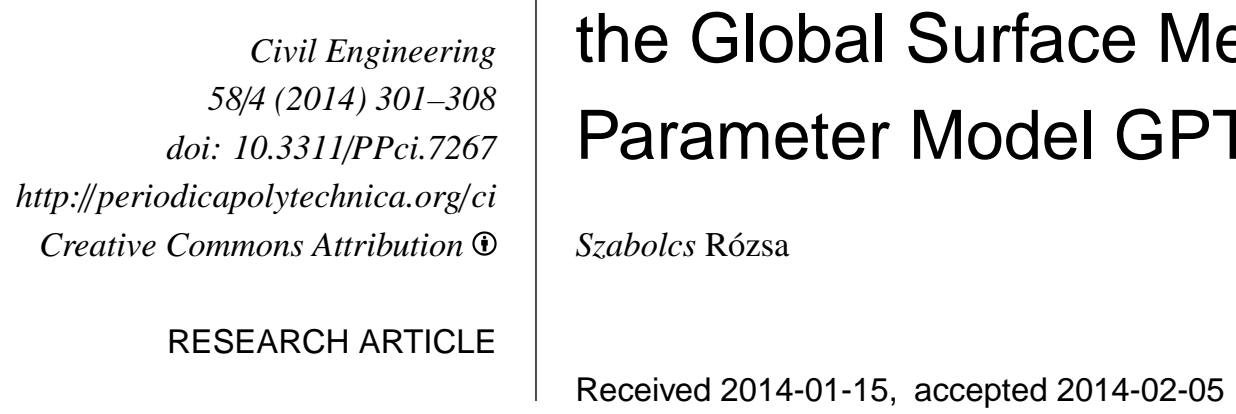

Received 2014-01-15, accepted 2014-02-05

\title{
Modelling Tropospheric Delays Using the Global Surface Meteorological Parameter Model GPT2
}

\begin{abstract}
In case of autonomous positioning the tropospheric delays are taken into consideration by 'blind' models. These models do not require any observed meteorological input parameters. Currently the Radio Transmission Commission for Aeronautics defines the Minimum Operational Performance Standards of GNSS, which includes a state-of-the-art blind tropospheric model, too.
\end{abstract}

Recently a new surface meteorological parameter model, the GPT2 has been released. Our study investigates the performance of this new model in the estimation of tropospheric delays using a global radiosonde data set for the period of 2010-2013.

Our results showed that GPT2 helped to remove more than $90 \%$ of the bias in tropospheric delay estimates found in the RTCA model. Moreover the uncertainties of the estimates are decreased by approximately 10\%. The validation showed that the performance of the tropospheric modelling using GPT2 is more stable geographically compared to the performance of the RTCA model.

\section{Keywords \\ GNSS $\cdot$ troposphere models $\cdot$ GPT2}

\section{Szabolcs Rózsa}

Department of Geodesy and Surveying, Budapest University of Technology and Economics, Múegyetem rkp. 3, H-1111 Budapest, Hungary

e-mail: rozsa.szabolcs@epito.bme.hu

\section{Introduction}

In the recent years Global Navigation Satellite Systems (GNSS) are being further developed to meet the strict requirements of Safety-of-Life (SoL) applications. These applications require not only higher accuracies in positioning, but the integrity of the satellite system must be monitored, too. Thus the modelling of the systematic error sources in satellite positioning must be continuously studied and improved in order to further enhance the accuracy of satellite positioning.

The lowest part of the atmosphere, the troposphere has a significant impact on the velocity of electromagnetic signals. Since the refractivity of this medium is larger than one, it causes a delay in the propagation of the satellite signals. This delay is a function of meteorological parameters along the signal profile. Unfortunately these parameters cannot be directly observed, therefore various models are used for the estimation of tropospheric delays as a function of surface meteorological parameters obtained either from a standard atmosphere model, from numerical weather prediction models (NWPs) or from real meteorological observations.

The modelling of tropospheric delays is carried out in different observation scenarios. In the first scenario an individual GNSS receiver computes its position autonomously (e.g. using the signals of the GNSS only). In this case a 'blind' troposphere model is used, when all of the input parameters are stored in the receiver's memory. The second scenario is the 'augmented' mode, when the positioning is done using additional information from either a Satellite Based Augmentation System (SBAS) or a Ground Based Augmentation System (GBAS). In the augmented mode additional meteorological parameters can be transmitted to the receivers, thus a refined tropospheric model can be applied in the positioning leading to higher positioning accuracies.

The blind models usually rely on standard atmospheric parameters or empirical models, which takes into consideration the seasonal variations of the meteorological parameters. Recently Lagler et al. [1] published a new version of the Global Pressure and Temperature model. In this model not only the annual, but the semi-annual variations of the surface meteorolog- 
ical parameters were taken into account. Our studies focus on the application of this new model in the determination of zenith tropospheric delays. The computed zenith tropospheric delays (ZTDs) are compared with state-of-the-art models, such as the one defined in RTCA standards [2]. Moreover the performance of GPT2 is compared to locally fitted 'blind' models derived from radiosonde observations, too.

The validation is carried out using a global data set of radiosonde observations. Since radiosondes provide 'in situ' observations of key meteorological parameters (total air pressure $-p$, ambient temperature $-T$ and dew point temperature $-T_{d}$ ) along a vertical profile, they can be used to compute zenith tropospheric delays.

Our study is outlined in the following way. Section 2 shortly introduces the theoretical background, including the algorithms of the tested troposphere models and the processing of radiosonde observations. The applied global radiosonde dataset is described in Section 3. Afterwards our investigations are described and finally the results are discussed.

\section{The determination of tropospheric delays}

The troposphere is a non-dispersive media for the propagation of microwave signals. The total tropospheric delay can be expressed as the integral of the refractivity of the air along the signal profile [3]:

$$
T D=10^{-6} \int N d s
$$

where $T D$ is the total tropospheric delay expressed in distance, $N$ is the refractivity of the air. The refractivity can be computed using an empirical model of meteorological parameters:

$$
N=k_{1} \frac{p_{d}}{T}+k_{2} \frac{e}{T}+k_{3} \frac{e}{T^{2}},
$$

where $p_{d}$ is the partial pressure of dry air, $e$ is the water vapour pressure, $T$ is the ambient temperature and $k_{1}, k_{2}$ and $k_{3}$ are empirical constants. According to Bevis et al. [4] the values of these constants are $0,7760 \mathrm{~K} / \mathrm{Pa}, 0,704 \mathrm{~K} / \mathrm{Pa}$ and $3739 \mathrm{~K}^{2} / \mathrm{Pa}$, respectively.

Due to the fact that the aforementioned meteorological parameters are not available along the signal path, the line integral needs to be estimated using various models utilizing surface meteorological data. In the next sections some recent models are briefly introduced.

\subsection{The Askne-Nordius model}

Askne and Nordius [5] published a model for the determination of tropospheric delays:

$$
T D=0.002276 \frac{p_{s}}{f(\phi, H)}+10^{-6} \int_{H}^{\infty}\left(k_{2}^{\prime} \frac{e}{T}+k_{3} \frac{e}{T^{2}}\right) d z
$$

where $p_{s}$ is the total surface pressure, $k_{2}^{\prime}$ and $f(\phi, H)$ are computed by:

$$
\begin{gathered}
k_{2}^{\prime}=k_{2}-k_{1} \frac{M_{w}}{M_{d}}=16.52 \mathrm{~K} / \text { mbar }, \\
f(\phi, H)=1-0.00266 \cos 2 \phi-0.00028 H,
\end{gathered}
$$

where $\phi$ is the latitude, $H$ is the height of the station expressed in kilometres referred to the geoid, $M_{w}$ and $M_{d}$ are the molar mass of water and dry air, respectively.

Based on the analysis of atmospheric profiles, Askne and Nordius [5] found the following expression for the zenith tropospheric delays:

$$
\begin{aligned}
& Z T D=10^{-6} \frac{k_{1} R_{d}}{g_{m}} p_{s}+ \\
& +10^{-6}\left[\frac{k_{2}^{\prime}}{k_{1}(\lambda+1)}+\frac{k_{3}}{k_{1}\left(\lambda+1-\alpha R_{d} / g_{m}\right)} T_{s}\right] e_{s},
\end{aligned}
$$

where $R_{d}$ is specific gas constant of dry air, $g_{m}$ is the gravity acceleration at the mass center of the atmospheric column above the GNSS antenna, $\lambda$ is the water vapour lapse rate, $\alpha$ is the temperature lapse rate and $T_{s}, e_{s}$ and $p_{s}$ are the temperature, water vapour pressure and total air pressure observations at the surface. The temperature and water vapour lapse rate values can be computed from vertical atmospheric profiles obtained from either radiosonde observations or numerical weather prediction models.

It must be noted that the first part of Eq. (6) is usually called the zenith hydrostatic delay (ZHD), while the second part is the zenith wet delay (ZWD).

\subsection{The RTCA MOPS tropospheric model}

The Radio Transmission Commission for Aeronautics defined the Minimum Operational Performance Standards for GNSS and augmentation systems used in the aeronautics. This standard defines the zenith hydrostatic delay and zenith wet delay at the zero altitude as:

$$
\begin{gathered}
Z_{\text {hyd }}=10^{-6} \frac{k_{1} R_{d} p_{s}}{g_{m}}, \\
Z_{w e t}=10^{-6} \frac{k_{3} R_{d}}{g_{m}(\lambda+1)-\alpha R_{d}} \frac{e_{S}}{T_{S}},
\end{gathered}
$$

where $k_{3}=382000 \mathrm{~K}^{2} / \mathrm{mbar}$, that slightly differs from the value given in $\mathrm{Eq}$ 2.

The five meteorological parameters $\left(p_{s}, T_{s}, e_{s}, \lambda\right.$ and $\left.\alpha\right)$ in the blind model are computed as a function of geographic latitude taking into consideration the seasonal variations using the following formula:

$$
\xi(\phi, D)=\xi_{0}(\phi)-\Delta \xi(\phi) \cdot \cos \left(\frac{2 \pi\left(D-D_{\min }\right)}{365.25}\right),
$$

where $D$ is the day-of-the-year, $D_{\min }=28$ for northern latitudes and $D_{\min }=211$ for southern latitudes. The parameters $\xi_{0}$ and $\Delta \xi$ 
are the average and seasonal variation values for the particular parameter at the receiver's latitude. These values can be found in [2].

The hydrostatic and wet delays at the altitude of the receiver are computed using the following equations:

$$
\begin{gathered}
Z H D=\left(1-\frac{\alpha H}{T}\right)^{\frac{g}{R_{d}^{\alpha}}} \cdot Z_{\text {hyd }}, \\
Z W D=\left(1-\frac{\alpha H}{T}\right)^{\frac{(\lambda+1) g}{R_{d^{\alpha}}}} \cdot Z_{\text {wet }},
\end{gathered}
$$

where $g=9.80665 \mathrm{~m} / \mathrm{s}^{2}$ and the receiver's height $(H)$ is expressed in units of meters above the geoid.

In case of positioning applications the zenith delays must be mapped to the satellite direction. The slant delays are computed as the product of the zenith delays and the mapping functions. A mapping function can be formulated above the elevation angle of $4^{\circ}$ as [2]:

$$
m\left(E l_{i}\right)=\frac{1.001}{\sqrt{0.002001+\sin ^{2}\left(E l_{i}\right)}},
$$

where $E l_{i}$ is the elevation angle of the satellite above the horizon of the receiver antenna.

\subsection{The GPT2 tropospheric model}

GPT2 is a global empirical model of surface meteorological parameters [1]. The model was derived from the latest ECMWF (European Center for Medium-Range Weather Forecast) ReAnalysis (ERA-Interim) [6]. Monthly mean profiles with the horizontal resolution of $1^{\circ}$ were processed in the period of 2001 2010. GPT2 provides estimates of the surface pressure, surface temperature, surface water vapour pressure and the temperature lapse rate by properly modelling the annual and semi-annual variations of these parameters. Contrary to the RTCA MOPS model, the phase of the seasonal variations is estimated, too. Each parameter can be computed using the following equation:

$$
\begin{aligned}
& r(t)=A_{0}+A_{1} \cos \left(\frac{D}{365.25} 2 \pi\right)+B_{1} \sin \left(\frac{D}{365.25} 2 \pi\right)+ \\
& +A_{2} \cos \left(\frac{D}{365.25} 4 \pi\right)+B_{2} \sin \left(\frac{D}{365.25} 4 \pi\right)
\end{aligned}
$$

where $A_{0}, A_{1}, A_{2}, B_{1}$ and $B_{2}$ are the mean value and the amplitudes of the annual and semi-annual variations of the individual parameters. The aforementioned parameters are available on a global grid with the resolution of $5^{\circ}$.

Unfortunately GPT2 does not provide the water vapour lapse rate estimations. Therefore additional assumptions should be made to use the model for the estimation of the wet delays. In our investigations, the parameters of GPT2 were supplemented by the RTCA estimates of water vapour lapse rates. Thus the total set of meteorological parameters required by the AskneNordius model could be created.

\subsection{The local blind troposphere model}

Since a global set of radiosonde observations were processed for the validation of the aforementioned troposphere models, this data set could also be used to derive locally fitted blind tropospheric models at the radiosonde launching sites. More than 13 years of data were analysed from 32 globally distributed radiosonde sites and the mean values, the amplitudes of the annual and semi-annual variations and their phase were estimated with a least-squares adjustment. Thus each parameter is expressed by the following equation:

$$
\begin{aligned}
r(t)=A_{0} & +A_{1} \cos \left(\frac{D}{365.25} 2 \pi+\frac{O_{1}}{365.25} 2 \pi\right)+ \\
& +B_{1} \sin \left(\frac{D}{365.25} 2 \pi+\frac{O_{1}}{365.25} 2 \pi\right)+ \\
& +A_{2} \cos \left(\frac{D}{365.25} 4 \pi+\frac{O_{1}}{365.25} 4 \pi\right)+ \\
& +B_{2} \sin \left(\frac{D}{365.25} 4 \pi+\frac{O_{1}}{365.25} 4 \pi\right)
\end{aligned}
$$

where the parameters $A_{0}, A_{1}, B_{1}, O_{1}, A_{2}$ and $B_{2}$ are the individual model parameters for the surface pressure, temperature, water vapour pressure, the temperature lapse rate and the water vapour lapse rate.

Using these locally fitted models, the aforementioned parameters can be estimated as a function of the day-of-the-year only. Thus the tropospheric delays can be computed by Eq (6) in a 'blind' mode. This model is referred as LOC later on.

Fig. 1 shows the annual variations of surface temperature estimated by the different blind models in Budapest. It can be clearly seen that GPT2 and LOC models fit better to the surface observations due to the proper estimation of the phase of the annual and semi-annual variations.

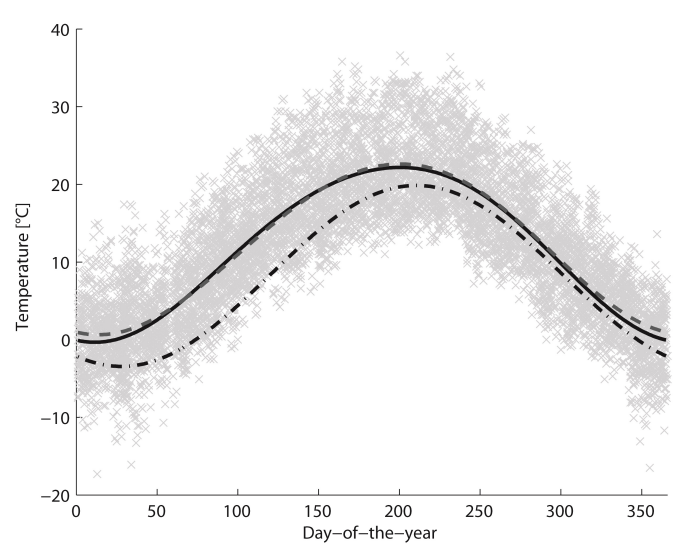

Fig. 1. Annual variations of surface temperature in Budapest (grey crosses: surface temperature observations between 2000 -2013; black dash-dot line: RTCA MOPS model; black solid line: GPT2 model; grey dashed line: local blind model)

\section{Data}

The performance of the blind troposphere models were tested using a global radiosonde data set obtained from the radiosonde database of the National Oceanic and Atmospheric Administration (NOAA). The observations of 32 stations were collected 
between January 1, 2000 and April 30, 2013 for the computations. Altogether 169,478 atmospheric profiles were processed in our study.

The local values of the hydrostatic and wet refractivity were computed at each level of the radiosonde profiles and these refractivity values were integrated along the whole profile to obtain the zenith tropospheric delays (Eq (1)). Since the burst altitudes of radiosondes are usually lower than the top of the stratosphere, therefore the delays caused by the atmospheric masses above the burst altitude of the balloon were taken into consideration using the International Standard Atmosphere [7]. An exhaustive description of this computation can be found in [8].

Since ZHD and ZWD values obtained from radiosonde profiles have the accuracy of a few millimetres [8], therefore these values were used as reference values in our studies.

Tab. 1. The list of the radiosonde sites used for the study.

\begin{tabular}{|c|c|c|c|c|c|}
\hline Location & WMOID & Lat $\left[{ }^{\circ}\right]$ & Lon $\left[^{\circ}\right]$ & Elev.[m] & No. of obs. \\
\hline Lulea & 02185 & 65.55 & 22.13 & 16 & 6177 \\
\hline Thule & 04202 & 76.53 & -68.75 & 77 & 3400 \\
\hline Madrid & 08221 & 40.47 & -3.58 & 638 & 8495 \\
\hline Budapest & 12843 & 47.43 & 19.18 & 139 & 8565 \\
\hline Fedorova & 20292 & 77.72 & 104.30 & 15 & 2124 \\
\hline Olenek & 24125 & 68.50 & 112.43 & 220 & 7687 \\
\hline Jakutsk & 24959 & 62.08 & 129.75 & 103 & 8365 \\
\hline St. Petersburg & 26063 & 59.97 & 30.30 & 4 & 8865 \\
\hline Mineraln'ye Vody & 37054 & 44.22 & 43.10 & 314 & 5580 \\
\hline Riyadh & 40437 & 24.93 & 46.72 & 612 & 5124 \\
\hline New Delhi & 42182 & 28.58 & 77.20 & 216 & 4349 \\
\hline Mumbai & 43003 & 19.12 & 72.85 & 14 & 714 \\
\hline Hong Kong & 45004 & 22.32 & 114.17 & 66 & 8127 \\
\hline Singapore & 48698 & 1.37 & 103.98 & 16 & 4381 \\
\hline Urumqi & 51463 & 43.78 & 87.62 & 919 & 3975 \\
\hline Bamako & 61291 & 12.53 & -7.95 & 381 & 2839 \\
\hline Mersa Matruh & 62306 & 31.33 & 27.22 & 30 & 2841 \\
\hline Pretoria & 68263 & -25.92 & 28.22 & 1500 & 4915 \\
\hline Gough Island & 68906 & -40.35 & -9.88 & 54 & 4409 \\
\hline Norman Wells & 71043 & 65.28 & -126.75 & 95 & 9113 \\
\hline Wallops Island & 72402 & 37.93 & -75.48 & 13 & 9687 \\
\hline Detroit & 72632 & 42.70 & -83.47 & 329 & 6787 \\
\hline Great Falls & 72776 & 47.45 & -111.38 & 1130 & 8724 \\
\hline Brasilia & 83378 & -15.87 & -47.93 & 1061 & 2202 \\
\hline Curitiba & 83840 & -25.52 & -49.17 & 908 & 5548 \\
\hline Lima & 84628 & -12.00 & -77.12 & 13 & 610 \\
\hline von Neumayer & 89002 & -70.67 & -8.25 & 40 & 4368 \\
\hline Halley & 89022 & -75.50 & -26.65 & 30 & 2277 \\
\hline Novolazarevskaja & 89512 & -70.77 & 11.83 & 102 & 5020 \\
\hline McMurdo & 89664 & -77.85 & 166.67 & 34 & 5507 \\
\hline Perth & 94610 & -31.93 & 115.95 & 29 & 3215 \\
\hline Melbourne & 94866 & -37.67 & 144.83 & 141 & 5488 \\
\hline
\end{tabular}

\section{Results}

After the computation of the reference ZHD and ZWD values from radiosonde profiles, the estimation of these values using the GPT2, RTCA and LOC models were done, and the results were compared to the numerically integrated reference values. The statistical properties of the residuals can be found in Table 2 and Table 3 for the ZHD and ZWD, respectively. The results show that the majority of the bias found in the RTCA estimates could be removed by the application of either GPT2 or LOC. The improvement reached the relative level of more than $90 \%$ for both the ZHD and the ZWD estimates. In terms of standard deviation a small improvement could be observed in the results. It must also be noted that the lowest bias for ZWD could be observed for the LOC model. This small improvement with respect to the GPT2 could be caused by the fact, that LOC provides an empirical model for the mean value and the annual and semi-annual variation of the water vapour lapse rate, too.

Tab. 2. The mean bias and the mean standard deviation of the ZHD estimates for the entire study period.

\begin{tabular}{lcc}
\hline Model & bias [mm] & std.dev. [mm] \\
\hline RTCA & -5.7 & \pm 18.5 \\
\hline GPT2 & -0.5 & \pm 16.9 \\
\hline LOC & +2.0 & \pm 16.9 \\
\hline
\end{tabular}

Tab. 3. The mean bias and the mean standard deviation of the ZWD estimates for the entire study period.

\begin{tabular}{ccc}
\hline Model & bias [cm] & std.dev. [mm] \\
\hline RTCA & -6.7 & \pm 4.3 \\
\hline GPT2 & 0.6 & \pm 3.7 \\
\hline LOC & 0.3 & \pm 3.7 \\
\hline
\end{tabular}

Fig. 3 shows the time series of the estimates for four stations located in different geographical latitudes. The stations are Thule (Greenland), Budapest (Hungary), Riyadh (Saudi Arabia) and Singapore. The time series clearly show that the GPT2 fits better to the ZHD and ZWD values derived from radiosonde observations than the original RTCA model. It must also be noted that the RTCA model specifies quite low seasonal variations for the arctic and the equatorial areas, thus the seasonal variation of ZHD is not represented at all in this model. Moreover in case of Riyadh and Singapore a small, but significant bias can be seen for the RTCA model, while GPT2 and LOC do not show this bias.

A good agreement was found between the GPT2 and LOC models for the ZWD, too. It can be seen that the modelling of the annual and semi-annual variations of the meteorological parameters improved the estimation of the zenith wet delays. The significant bias of the RTCA model can be clearly seen in the lower latitude area (Riyadh and Singapore).

Fig. 4 and Fig. 5 show the latitude dependency of the bias and the standard deviation of ZHD and ZWD residuals, respectively. Concerning the ZHD estimates, a large bias can be observed for the stations located close to, or on the Antarctica for the RTCA model, while the GPT2 and LOC models showed almost the same absolute value of bias on the southern as well as on the northern hemisphere. The standard deviation of the ZHD 


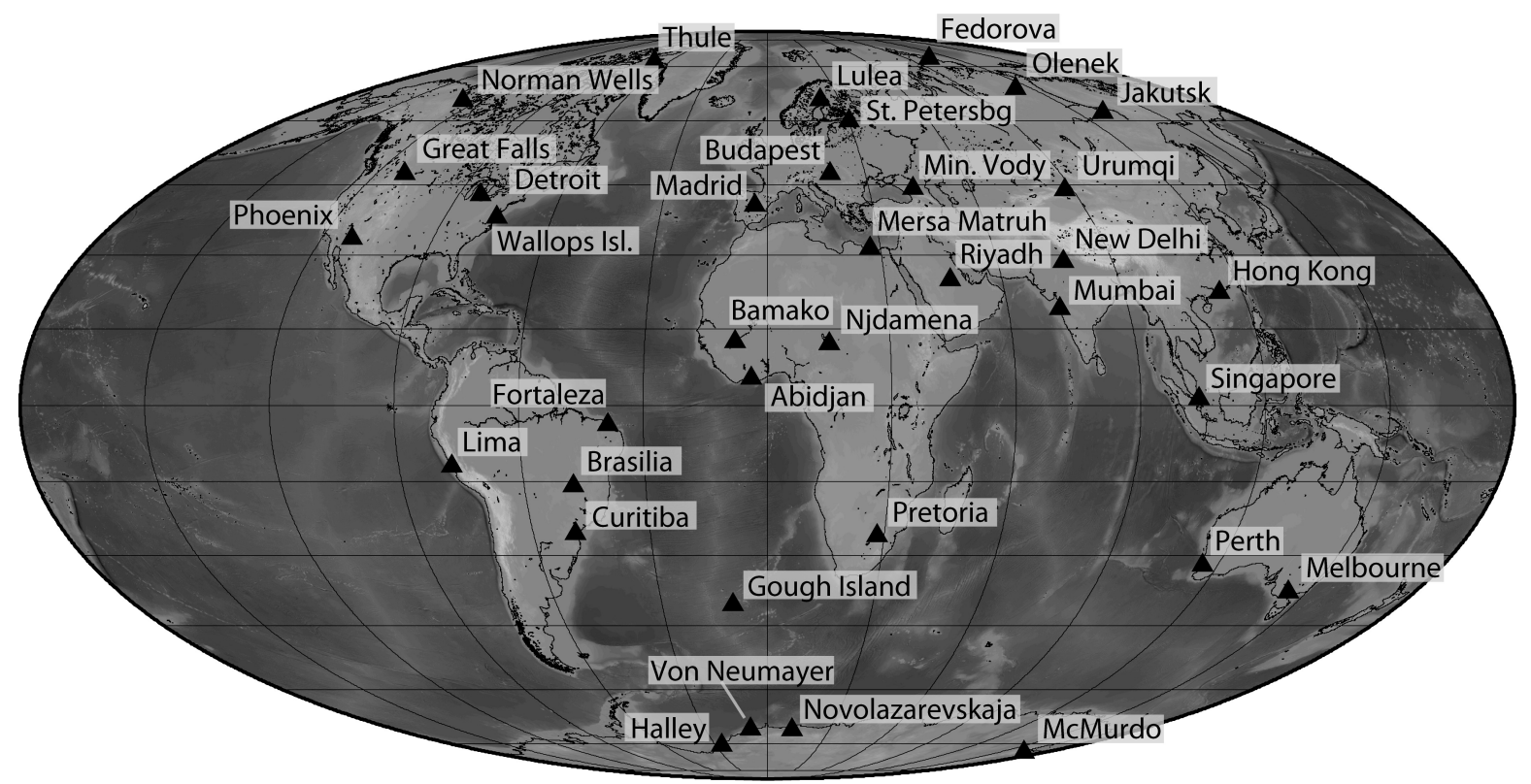

Fig. 2. The location of the radiosonde sites

estimates shows a significant latitude dependency. All of the models provide higher uncertainties on higher latitudes.

The analysis of ZWD estimates showed that the RTCA model shows significant bias on the southern hemisphere and in lower latitudes of the northern hemisphere, too. The performances of GPT2 and LOC are more stable globally. A slight increase in bias can be observed on the equatorial area only. In terms of standard deviation the results showed the well-known trend with respect to the geographical latitude. The uncertainty of the modelling of wet delays is higher close to the Equator, mainly due to the higher humidity of the air.

\section{Conclusions}

Our investigations proved that the GPT2 model is appropriate for modelling the tropospheric delays in GNSS positioning. The currently widely accepted RTCA model showed large biases in the zenith hydrostatic delays as well as in the zenith wet delays. More than $90 \%$ of this bias could be eliminated by the application of the GPT2 model.

In terms of standard deviation GPT2 improved the tropospheric delay modelling by $9 \%$ and $14 \%$ for the ZHD and ZWD, respectively. Thus not only the systematic error, but also the uncertainty of the estimations could be improved globally. It must be emphasized that the performance of GPT2 is more stable compared to the performance of the RTCA model. The prior does not show any significant difference in the performance on the southern and the northern hemisphere.

The locally derived blind tropospheric models (LOC) showed comparable biases and uncertainties to GPT2. The LOC model showed the smallest bias in case of the ZWD estimations, which could be caused by the fact that this was the only model, which incorporated the estimation of the annual and semi-annual variations of water vapour lapse rates.

Based on these results it can be concluded that currently
GPT2 is the most appropriate blind model for the estimation of tropospheric delays in satellite positioning. However the estimation of the annual and semi-annual terms of water vapour lapse rates should be incorporated in the model to enhance the estimation of tropospheric wet delays in the future.

\section{Acknowledgement}

The author acknowledges the kind support of the Hungarian Research Fund under the contract K-83909. This work is linked with the "Development of quality-oriented and harmonized $\mathrm{R}+\mathrm{D}+\mathrm{I}$ strategy and functional model at BME" project. This project is supported by the New Hungary Development Plan (Project ID: TÁMOP-4.2.1/B-09/1/KMR-2010-0002).

This work is linked with the ESA project TROPSY: Assessment Techniques of tropospheric effects for local augmentation systems. 

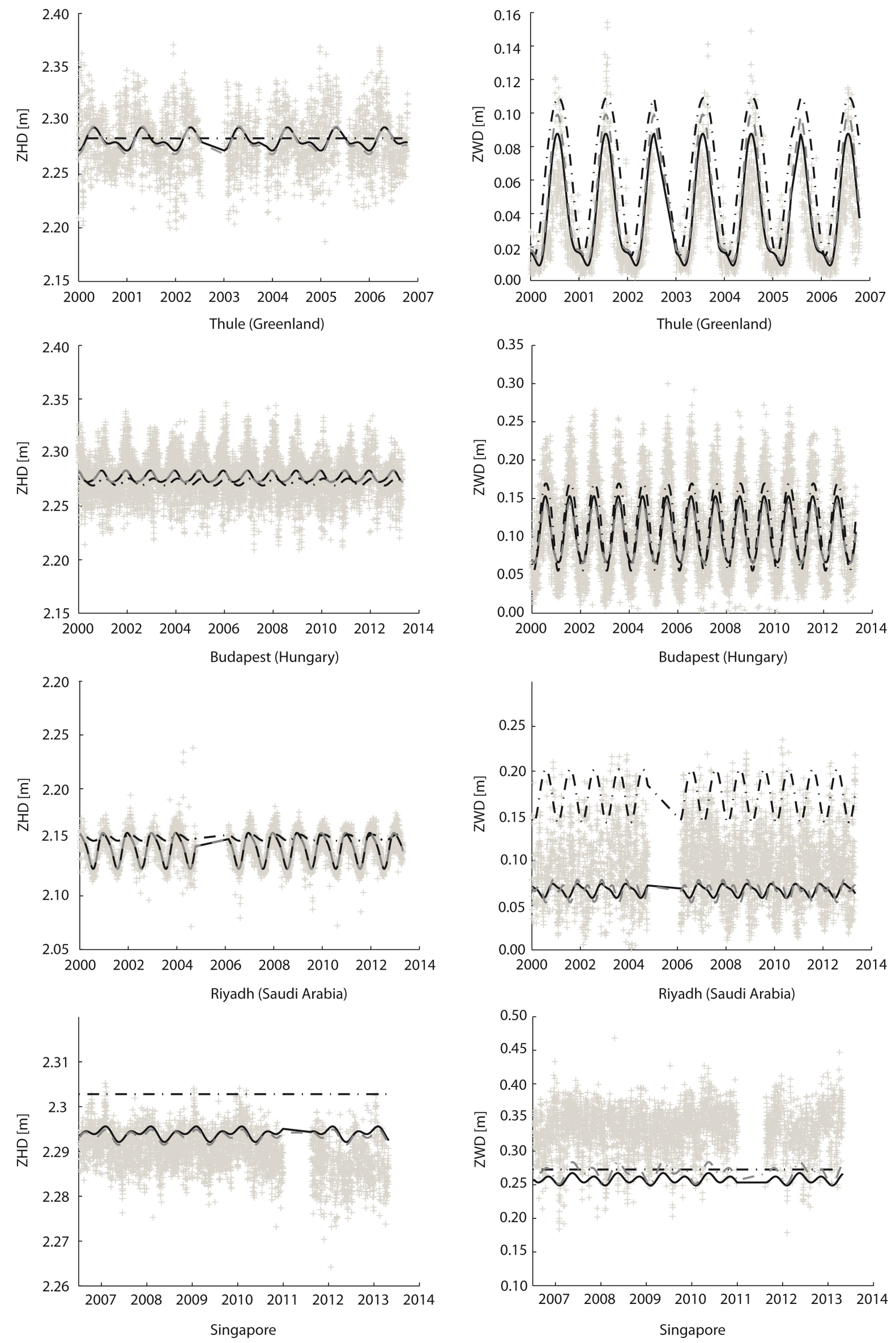

Fig. 3. Time series of ZHD and ZWD estimations at Thule (Greenland), Budapest (Hungary), Riyadh (Saudi Arabia) and Singapore (dash-dot line: RTCA

model; black solid line: GPT2 model; grey dashed line: LOC model) 


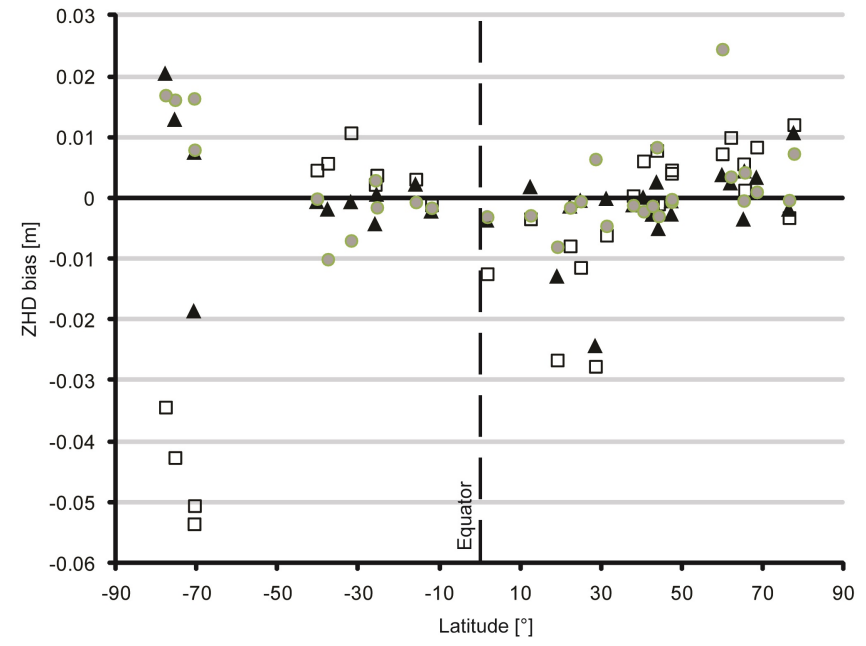

Fig. 4. Latitude dependency of the bias and standard deviation of ZHD estimates (black square: RTCA model; black triangle: GPT2 model; grey circle:

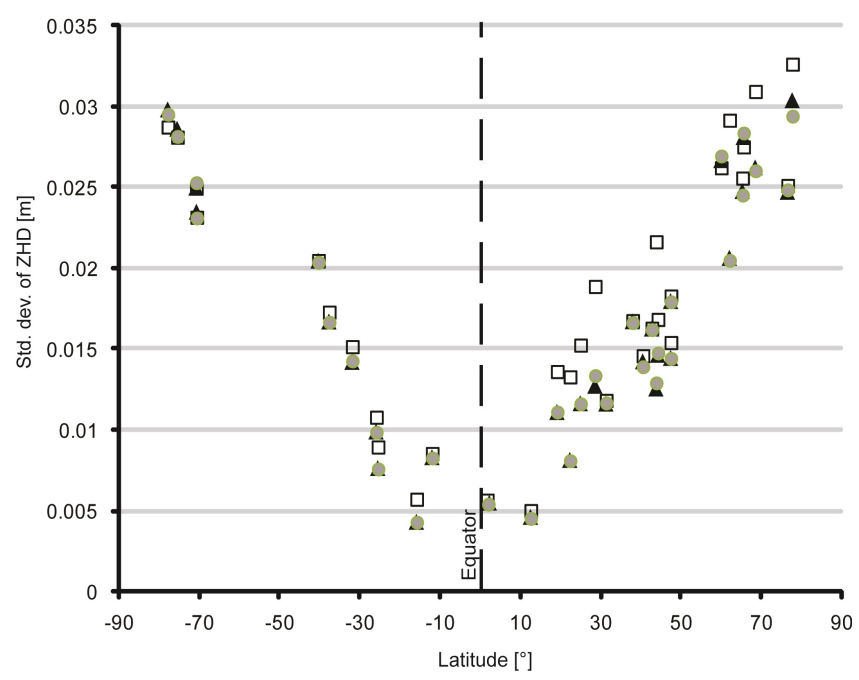

LOC model)

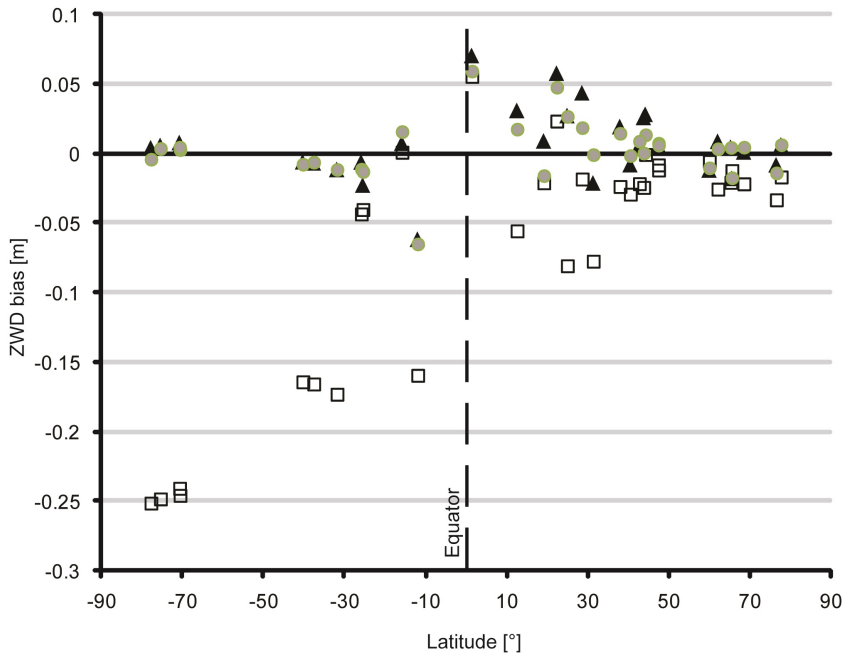

Fig. 5. Latitude dependency of the bias and standard deviation of ZWD estimates (black square: RTCA model; black triangle: GPT2 model; grey circle:

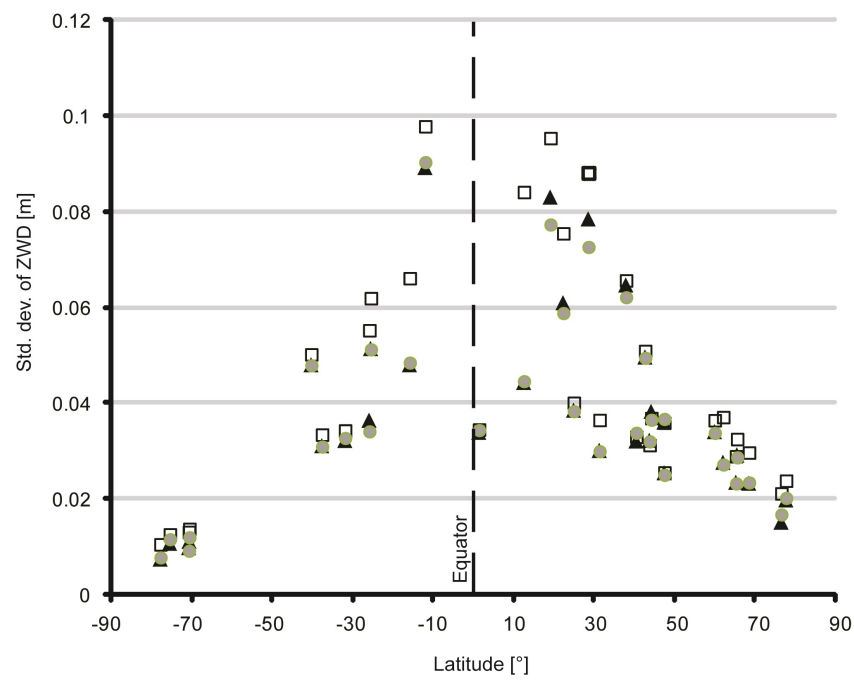

LOC model) 


\section{References}

1 Lagler K, Schindelegger M, Böhm J, Krásná H, Nilsson T, GPT2: Empirical slant delay model for radio space geodetic techniques, Geophysical Research Letters, 40, (2013), 1069-1073, DOI 10.1002/grl.50288

2 Minimum Operational Performance Standards for Global Positioning System/Satellite-Based Augmentation System Airborne Equipment, Radio Transmission Commission for Aeronautics, 2006. RTCA DO-229D.

3 Thayer GD, An improved equation for the radio refractive index of air, Radio Science, 9, (1974), 803-807, DOI 10.1029/RS009i010p00803

4 Bevis M, Businger S, Herring T, Rocken C, Anthes A, Ware R, GPS meteorology: Remote sensing of atmospheric water vapour using the global positioning system, Journal of Geophysical Research, 97, (1992), 15787-15801, DOI $10.1029 / 92 J D 01517$

5 Askne J, Nordius H, Estimation of tropospheric delay for microwaves from surface weather data, Radio Science, 22, (1987), 379-386, DOI 10.1029/RS022i003p00379

6 Dee DP, Uppala SM, Simmons AJ, Berisford P, Poli P, Kobayashi S, Andrae U, Balmaseda MA, Balsamo G Bauer, P B P, Beljaars ACM, van de Berg L, Bidlot J, Bormann N, Delsol C, Dragani R, Fuentes M, Geer AJ, Haimberger L, Healy SB, Hersbach H, Hólm EV, Isaksen L, Kallberg P, Köhler M, Mtricardi M, McNally AP, Monge-Sanz BM, Morcrette J-J, Park B-K, Peubey C, de Rosnay P, Tavolato C, Thépaut J$\mathbf{N}$, Vitart $\mathbf{F}$, The ERA-Interim reanalysis: configuration and performance of the data assimilation system, Quarterly Journal of the Royal Meteorological Society, 137, (2011), 553-597, DOI $10.1002 / \mathrm{qj} .828$

7 Standard Atmosphere, International Organization for Standardization, 1975. ISO2533:1975.

8 Rózsa S, Uncertainty considerations for the comparison of water vapour derived from radiosondes and GNSS, IAG Symposia Series, 139, (2013), 6580, DOI 10.1007/978-3-642-37222-3-9 